\title{
HUBUNGAN WAKTU TUNGGU DAN SIKAP PETUGAS DENGAN KEPUASAN PASIEN DI INSTALASI FARMASI RUMAH SAKIT ISLAM SURABAYA (RSIS) JEMURSARI
}

\author{
Agus Aan Adriansyah' ${ }^{1}$, Ima Nadatien ${ }^{2}$ \\ ${ }^{1}$ Program Studi S1 Ilmu Kesehatan Masyarakat, Fakultas Kesehatan \\ ${ }^{2}$ Program Studi S1 Keperawatan, Fakultas Keperawatan dan Kebidanan \\ Universitas Nahdlatul Ulama Surabaya \\ Email: aan.naufa187@unusa.ac.id
}

\begin{abstract}
Jemursari Surabaya Islamic Hospital has a Pharmacy Installation service that requires long prescription service waiting times. This resulted in the emergence of patient dissatisfaction with the quality of services available at the Jemursari Islamic Hospital Pharmacy Installation in Surabaya. In relation to patient satisfaction and the quality of service at the Jemursari Islamic Hospital, there are still patients who are dissatisfied with the services of the Jemursari Islamic Hospital Pharmacy Installation staff. This study aims to analyze the relationship between waiting time and the attitude of the officer with patient satisfaction at the Jemursari Islamic Hospital Pharmacy Installation in Surabaya. The study was an observational analytic study using aapproach cross sectional. The research locations were in Depo 1 Pharmacy Installation, Jemursari Islamic Hospital, Jl Jemursari no. 51-57, Jemur Wonosari, Wonocolo, Surabaya City, East Java. The research sample was 100 respondents using random sampling techniques. The data obtained were then analyzed using thetest chi square. The results of the study showed that there was a significant relationship between service waiting time and the attitude of the officers in the service at the Pharmacy Installation with the level of satisfaction felt. Waiting time for services at Depo 1 Pharmacy is not in accordance with the Standard Minimum Procedure that has been determined. The conclusion of this study is the waiting time and attitude of the officers have a significant relationship to patient satisfaction.
\end{abstract}

Keywords: Waiting Time, Officer Attitude, Patient Satisfaction

\begin{abstract}
ABSTRAK
Rumah Sakit Islam Jemursari Surabaya mempunyai pelayanan Instalasi Farmasi yang membutuhkan waktu tunggu pelayanan resep yang lama. Hal ini mengakibatkan munculnya ketidakpuasan pasien terhadap kualitas pelayanan yang ada di Instalasi Farmasi Rumah Sakit Islam Jemursari Surabaya. Dalam hubungannya dengan kepuasan pasien dan kualitas pelayanan Rumah Sakit Islam Jemursari, masih terdapat pasien yang merasa tidak puas dengan pelayanan petugas Instalasi Farmasi Rumah Sakit Islam Jemursari. Penelitian ini bertujuan untuk menganalisis hubungan waktu tunggu dan sikap petugas dengan kepuasan pasien pada Instalasi Farmasi Rumah Sakit Islam Jemursari Surabaya. Penelitian ini merupakan penelitian observasional analitik dengan menggunakan pendekatan cross sectional. Lokasi penelitian berada di Instalasi Farmasi Depo 1, Rumah Sakit Islam Jemursari, Jl Jemursari no 51-57, Jemur Wonosari, Wonocolo, Kota Surabaya, Jawa Timur. Sampel penelitian sebesar 100 responden dengan menggunakan teknik random
\end{abstract}


sampling. Data yang diperoleh kemudian dianalisis dengan menggunakan uji chi square. Hasil penelitian menunjukkan bahwa terdapat hubungan yang signifikan antara waktu tunggu pelayanan dan sikap petugas pada pelayanan di Instalasi Farmasi dengan tingkat kepuasan yang dirasakan. Waktu tunggu pelayanan di Depo 1 Farmasi tidak sesuai dengan Standar Prosedur Minimal yang telah ditentukan. Waktu tunggu dan sikap petugas memiliki hubungan yang signifikan terhadap kepuasan pasien.

Kata kunci: Waktu Tunggu, Sikap Petugas, Kepuasan Pasien.

\section{PENDAHULUAN}

Rumah sakit di tuntut untuk menghadapi perubahan atas kondisi semakin maju dan berkembangnya dunia kesehatan terutama di bidang pelayanan kesehatan rumah sakit. Hal tersebut terjadi karena Munculnya kesempatan untuk memilih layanan kesehatan yang terbaik menurut pandangan pengguna yang disebabkan oleh adanya peningkatan biaya kesehatan, dan persaingan yang semakin ketat kemudian di dasarkan dari pemikiran pengguna layanan kesehatan saat ini yang semakin kritis.

Sehingga salah satu upaya untuk dapat bertahan mengikuti perubahan pelayanan adalah dengan menetapkan strategi pemasaran yang tidak saja berlaku bagi organisasi kesehatan swasta namun juga berlaku untuk organisasi kesehatan pemerintah agar dapat menghasilkan layanan kesehatan yang berkualitas.

Pelayanan yang berkualitas tentu saja tidak hanya senyum ramah dari pegawai saja, melainkan lebih dari itu. Menurut Parasuraman, Zeithaml dan Berry (2013) terdapat lima dimensi utama yang relevan untuk menjelaskan kualitas pelayanan yang dikenal dengan service quality (servqual) yaitu, tangible (bukti fisik), reliability (kehandalan), responsiveness (daya tanggap), assurance (jaminan), dan emphaty (empati). Kelima dimensi kualitas pelayanan tersebut merupakan kunci utama untuk meningkatkan kepuasan pasien. ${ }^{1}$ Masyarakat selalu berharap agar pelayanan Rumah Sakit, baik milik pemerintah maupun swasta dapat memberikan pelayanan yang baik dan memuaskan bagi setiap pengguna yang memanfaatkannya. Pasien menginginkan fasilitas yang baik dari Rumah Sakit, keramahan pihak Rumah Sakit, serta ketanggapan, kemampuan, dan kesungguhan para petugas Rumah Sakit. Oleh karena itu, pihak Rumah Sakit dituntut untuk selalu berusaha meningkatkan layanan kepada pasien.

Rumah Sakit Islam Jemursari Surabaya mempunyai pelayanan Instalasi Farmasi membutuhkan waktu tunggu pelayanan resep yang lama. Hal ini mengakibatkan munculnya ketidakpuasan pasien terhadap kualitas pelayanan yang ada di Instalasi Farmasi Rumah Sakit Islam Jemursari Surabaya. Tidak adanya perbaikan terhadap pelayanan yang cepat dan tanggap, dapat berpengaruh pada kualitas 
pelayanan rumah sakit. Data waktu tunggu pelayanan resep pasien BPJS rawat jalan pada Instalasi Farmasi Rumah Sakit Islam Jemursari Surabaya berdasarkan kategori waktu tunggu resep tahun 2016-2017, dapat diketahui bahwa jumlah resep yang masuk ke Depo 1 Instalasi Farmasi Rumah Sakit Islam Jemursari Surabaya pada tahun 2017 sebanyak 118.994 resep. Gambaran waktu tunggu pada tahun 2017 masih melebihi standar yang telah di tetapkan dalam surat Keputusan Menteri Kesehatan RI. Nomor. 129/Menkes/II/2008 tentang standar pelayanan minimal rumah sakit. ${ }^{2}$ Penelitian ini bertujuan menganalisis hubungan waktu tunggu dan sikap petugas dengan kepuasan pasien pada Instalasi Farmasi Rumah Sakit Islam Jemursari Surabaya.

\section{METODE PENELITIAN}

Desain penelitian ini menggunakan observasional analitik dengan pendekatan cross sectional, karena observasi atau pengumpulan data pada suatu saat artinya setiap subjek penelitian di observasi satu kali pada saat pengamatan. Populasi penelitian ini adalah pasien BPJS rawat jalan Instalasi Farmasi Rumah Sakit Islam Jemursari khususnya pada Depo 1 yang berkunjung setiap bulannya di tahun 2018 yang berjumlah 9280 pasien.

Sampel pada penelitian ini adalah sebagian pasien yang berada di ruang tunggu pelayanan resep Instalasi Farmasi Rumah Sakit Islam Jemursari khususnya Depo 1 yang menjadi responden dalam penelitian ini. Basar sampel yang dijadikan responden penelitian adalah sebesar 100 pasien. Teknik pengambilan sampel dilakukan dengan random sampling dari pasien BPJS dengan melihat nomer antrian kelipatan yang akan dijadikan sampel sebanyak 100 responden yang sudah ditetapkan.

Data penelitian merupakan data primer. Pengumpulan data dilakukan dengan instrumen kuesioner. Analisis data dilakukan terhadap setiap variabel penelitian. Data yang telah diperoleh dianalisis dan diinterpretasikan untuk menguji hipotesis dengan menggunakan aplikasi komputer (software) statistik. Analisis yang dilakukan meliputi analisis univariat bertujuan untuk mengetahui distribusi frekuensi dan proporsi dari variabel waktu tunggu dan sikap petugas, serta kepuasan pasien. Analisis selanjutnya adalah analisis bivariat dilakukan untuk menilai hubungan antara waktu tunggu dan sikap petugas terhadap kepuasan pasien.

\section{HASIL DAN PEMBAHASAN}

\section{Waktu Tunggu Pasien}

Karakteristik pasien berdasarkan waktu tunggu dalam penelitian di Rumah Sakit Islam Surabaya (RSIS) Jemursari dapat dilihat pada Tabel 1. Berikut ini.

Tabel 1. Karakteristik Responden Berdasarkan Waktu Tunggu di RSIS Jemursari

\begin{tabular}{lccc}
\hline No. & $\begin{array}{c}\text { Waktu Tunggu } \\
\text { Pelayanan }\end{array}$ & Frekuensi & Persentase \\
\hline 1. & Tidak sesuai SPM & 54 & 54,0 \\
2. & Sesuai SPM & 46 & 46,0 \\
\hline & Total & 100 & 100,0 \\
\hline
\end{tabular}


Berdasarkan Tabel 1. menunjukkan bahwa responden yang turut berpartisipasi dalam penelitian sebagian besar $(54,0 \%)$ menyatakan bahwasannya waktu tunggu pelayanan di Depo 1 Farmasi tidak sesuai dengan Standar Prosedur Minimal yang telah ditentukan. Menurut Permenkes RI No. 129/Menkes/SK/II 2008, waktu tunggu pelayanan adalah waktu yang diperlukan mulai dari pasien memberikan resep kepetugas sampai diberikan obat dan KIE, dengan standar waktu tunggu untuk obat racikan $\leq 60$ menit dan obat non racikan $\leq 30$ menit. $^{2}$

\section{Sikap Petugas}

Karakteristik responden berdasarkan sikap dapat dilihat pada Tabel 2.

Tabel 2. Karakteristik Responden Berdasarkan Sikap Petugas Pelayanan Farmasi di RSIS Jemursari

\begin{tabular}{cccc}
\hline No. & Sikap Petugas & Frekuensi & Persentase \\
\hline 1. & Cukup Baik & 54 & 54,0 \\
2. & Baik & 46 & 46,0 \\
\hline & Total & 100 & 100,0 \\
\hline
\end{tabular}

Tabel 2. menunjukkan bahwa responden yang turut berpartisipasi dalam penelitian sebagian besar $(54,0 \%)$ menyatakan bahwa sikap petugas pelayanan di Depo 1 Farmasi dinilai cukup baik dalam memberikan pelayanan dan hanya $46,0 \%$ yang mendapatkan penilaian baik oleh responden. Sikap dari seorang petugas pelayanan kesehatan merupakan salah satu faktor yang menentukan apakah pelayanan yang diberikan bermutu atau tidak, sehingga dengan sikap petugas yang ramah dan baik dalam memberikan pelayanan dapat menjadi penentu dari kesembuhan seorang pasien, sebaliknya sikap petugas yang kasar dan tidak acuh dapat mengurangi kepuasan pasien terhadap pelayanan yang diterimanya. $^{3}$

\section{Kepuasan Pasien}

Karakteristik responden berdasarkan tingkat kepuasan dapat dilihat pada Tabel 3.

Tabel 3. Karakteristik Responden Berdasarkan Tingkat Kepuasan di RSIS Jemursari

\begin{tabular}{cccc}
\hline No. & Tingkat Kepuasan & Frekuensi & Persentase \\
\hline 1. & Cukup Puas & 52 & 52,0 \\
2. & Puas & 48 & 48,0 \\
\hline & Total & 100 & 100,0 \\
\hline
\end{tabular}

Tabel 3. menunjukkan bahwa responden yang turut berpartisipasi dalam penelitian sebagian besar $(52,0 \%)$ menyatakan bahwa mereka menyatakan hanya sekadar cukup puas terkait pelayanan di Depo 1 Farmasi. Kepuasan pasien telah dipertimbangkan untuk menjadi salah satu focus yang diinginkan pada pelayanan kesehatan. Menurut Notoatmodjo (2007), faktor-faktor yang mempengaruhi kepuasan yaitu pengetahuan, kesadaran, sikap positif, sosial ekonomi, sistem nilai, pemahaman pasien tentang jenis pelayanan yang akan diterimanya, dan empati yang ditujukan oleh pemberi pelayanan kesehatan. ${ }^{4}$

\section{Waktu Tunggu dengan Kepuasan Pasien}

Ketertkaitan antara waktu tunggu dengan kepuasan pasien dapat dilihat pada Tabel 4. 
Tabel 4. Tabulasi Silang antara Waktu Tunggu dengan Kepuasan Pasien pada Instalasi Farmasi RSIS Jemursari

\begin{tabular}{|c|c|c|c|c|c|c|c|}
\hline \multirow[t]{3}{*}{ No. } & \multirow[t]{3}{*}{ Waktu Tunggu } & \multicolumn{4}{|c|}{ Kepuasan Pasien } & \multicolumn{2}{|c|}{ Total } \\
\hline & & \multicolumn{2}{|c|}{ Cukup Puas } & \multicolumn{2}{|c|}{ Puas } & \multirow[b]{2}{*}{$\mathrm{n}$} & \multirow[b]{2}{*}{$\%$} \\
\hline & & $\mathrm{n}$ & $\%$ & $\mathrm{n}$ & $\%$ & & \\
\hline 1. & Tidak sesuai SPM & 49 & 90,7 & 5 & 9,3 & 54 & 100,0 \\
\hline 2. & Sesuai SPM & 3 & 6,5 & 43 & 93,5 & 46 & 100,0 \\
\hline & Total & 52 & 52,0 & 48 & 48,0 & 100 & 100,0 \\
\hline \multicolumn{8}{|c|}{$\begin{array}{c}\text { Fisher's Exact Test }=0,001(<0,05) \\
\text { Cramer's } V=0,840 \\
\text { OR }=0,099\end{array}$} \\
\hline
\end{tabular}

Berdasarkan Tabel 4. dapat diinformasikan bahwa semakin sesuai waktu tunggu untuk mendapatkan obat (sesuai standar SPM), maka semakin puas pasien dalam menilai pelayanan di instalasi farmasi RSIS Jemursari. Oleh sebab itu, jika dalam proses menunggu layanan obat selesai sesuai dengan aturan yang ada, yaitu 30 menit untuk obat non racikan dan 60 menit untuk obat racikan, maka pasien akan puas dengan pelayanan yang diberikan.

Waktu tunggu pada pelayanan resep sangat tergantung pada ketanggapan, kemauan, kesiapan, sikap, kecepatan petugas, dan jumlah petugas dalam memberikan pelayanan serta ketepatan waktu dari pelayanan sangat mempengaruhi kepuasan pasien dalam kebutuhan untuk mendapatkan pelayanan di rumah sakit. $^{5}$

Hasil crosstabulasi silang tersebut juga didukung secara statistik berdasarkan parameter Fisher's Exact Test yang didapatkan nilai signifikansi sebesar 0,001 $(<0,05)$. Hasil ini menunjukkan bahwa terdapat hubungan yang signifikan antara waktu tunggu pelayanan di Instalasi Farmasi dengan tingkat kepuasan yang dirasakan. Kekuatan hubungan juga dapat diketahui dari parameter Cramer's $V$ yang menunjukkan nilai 0,840 yang menandakan hubungan kedua variabel tersebut adalah kuat. Secara Odd Ratio dapat disimpulkan bahwa jika waktu tunggu pelayanan di instalasi farmasi semakin sesuai dengan SPM (Standar Pelayanan Minimal), maka pasien akan cenderung merasakan puas sebesar 0,099x dibandingkan jika waktu tunggu pelayanan yang tidak sesuai dengan SPM.

Hasil penelitian ini senada dengan yang dilakukan oleh Megawati, et al. (2016) yang menyatakan bahwa ada korelasi tingkat kepuasan umum dengan persepsi ketujuh dimensi mutu pelayanan farmasi rawat jalan (sikap petugas, pemberian informasi obat, ketersediaan obat, fasilitas, lokasi, waktu tunggu pelayanan obat dan harga obat) di RS Baptis Batu, baik pada seluruh responden, maupun pada kelompok pasien un-insured maupun yang terasuransi BPJS-K. ${ }^{6}$

\section{Sikap Petugas dengan Kepuasan Pasien}

Ketertkaitan antara sikap petugas dengan kepuasan pasien dapat dilihat pada Tabel 5. 
Tabel 5. Tabulasi Silang antara Sikap Petugas dengan Kepuasan Pasien pada Instalasi Farmasi RSIS Jemursari

\begin{tabular}{|c|c|c|c|c|c|c|c|}
\hline \multirow[t]{3}{*}{ No. } & \multirow[t]{3}{*}{ Sikap Petugas } & \multicolumn{4}{|c|}{ Kepuasan Pasien } & \multicolumn{2}{|c|}{ Total } \\
\hline & & \multicolumn{2}{|c|}{ Cukup Puas } & \multicolumn{2}{|c|}{ Puas } & \multirow[b]{2}{*}{$\mathrm{n}$} & \multirow[b]{2}{*}{$\%$} \\
\hline & & $\mathrm{n}$ & $\%$ & $\mathrm{n}$ & $\%$ & & \\
\hline 1. & Cukup Baik & 52 & 96,3 & 2 & 3,7 & 54 & 100,0 \\
\hline 2. & Baik & 0 & 0,0 & 46 & 100,0 & 46 & 100,0 \\
\hline & Total & 52 & 52,0 & 48 & 48,0 & 100 & 100,0 \\
\hline \multicolumn{8}{|c|}{$\begin{array}{c}\text { Fisher's Exact Test }=0,001(<0,05) \\
\text { Cramer's } V=0,961 \\
O R=0,037\end{array}$} \\
\hline
\end{tabular}

Berdasarkan Tabel 5 dapat diinformasikan bahwa semakin baik sikap petugas dalam memberikan pelayanan obat, maka semakin puas pula pasien dalam menilai pelayanan di instalasi farmasi RSIS Jemursari. Oleh sebab itu, jika petugas senantiasa menunjukkan sikap yang baik dalam proses memberikan pelayanan obat, maka pasien akan senantiasa puas dengan pelayanan yang diberikan pada unit farmasi tersebut.

Hasil tabulasi silang tersebut juga didukung secara statistik berdasarkan parameter Fisher's Exact Test yang didapatkan nilai signifikansi sebesar 0,001 $(<0,05)$. Hasil ini menyimpulkan bahwa secara statistik juga menunjukkan terdapat hubungan yang signifikan antara sikap petugas pada pelayanan di Instalasi Farmasi dengan tingkat kepuasan yang dirasakan. Kekuatan hubungan juga dapat diketahui dari parameter Cramer's $V$ yang menunjukkan nilai 0,961 yang menandakan hubungan kedua variabel tersebut adalah sangat kuat. Secara Odd Ratio dapat disimpulkan bahwasannya jika sikap petugas pada pelayanan di instalasi farmasi semakin baik, maka pasienakan cenderung merasakan puas sebesar 0,037x dibandingkan jika sikap petugas hanya sekadar cukup baik.

Hasil penelitian ini sependapat dengan Wiyono (2000) bahwa sikap dari seorang petugas pelayanan kesehatan merupakan salah satu faktor yang menentukan apakah pelayanan yang diberikan bermutu atau tidak, sehingga dengan sikap petugas yang ramah dan baik dalam memberikan pelayanan dapat menjadi penentu dari kesembuhan seorang pasien, sebaliknya sikap petugas yang kasar dan tidak acuh dapat mengurangi kepuasan pasien terhadap pelayanan yang diterimanya. ${ }^{3}$ Jacobalis menyatakan bahwa mutu yang baik dikaitkan dengan kesembuhan penyakit, kecepatan pelayanan, lingkungan yang menyenangkan, keramahan petugas serta biaya yang terjangkau. Diantara faktor-faktor tersebut ternyata keramahan petugas menentukan tingkat kepuasan pasien terhadap pelayanan yang dirasakan. ${ }^{7}$ 


\section{SIMPULAN DAN SARAN}

\section{Simpulan}

1. Sebagian besar responden berjenis kelamin perempuan, berumur $>41$ tahun, memiliki pekerjaan sebagai wiraswasta, dan hampir sebagian besar memiliki latar belakang pendidikan terakhir SMA/SMK serta memiliki tingkat pendapatan antara $\mathrm{Rp}$. 3.000.000 hingga Rp. 5.000.000. Responden yang turut berpartisipasi dalam penelitian mayoritas merupakan pasien dengan kategori pengambilan resep non racikan di Depo Farmasi.

2. Sebagian besar responden menyatakan bahwa waktu tunggu pelayanan di Depo 1 Farmasi tidak sesuai dengan Standar Prosedur Minimal yang telah ditentukan.

3. Sebagian besar responden menyatakan bahwa sikap petugas pelayanan di Depo 1 Farmasi dinilai cukup baik dalam memberikan pelayanan.

4. Sebagian besar responden menyatakan bahwasannya mereka menyatakan hanya sekadar cukup puas terkait pelayanan di Depo 1 Farmasi.

5. Secara statistik dapat diinformasikan bahwa:

a. Terdapat hubungan yang kuat dan signifikan antara waktu tunggu pelayanan di Instalasi Farmasi dengan tingkat kepuasan yang dirasakan. Apabila waktu tunggu pelayanan di instalasi farmasi semakin sesuai dengan SPM (Standar Pelayanan Minimal), maka pasien akan cenderung merasakan puas sebesar 0,099x dibandingkan jika waktu tunggu pelayanan yang tidak sesuai dengan SPM.

b. Terdapat hubungan yang sangat kuat dan signifikan antara sikap petugas pada pelayanan di Instalasi Farmasi dengan tingkat kepuasan yang dirasakan. Apabila sikap petugas pada pelayanan di instalasi farmasi semakin baik, maka pasien akan cenderung merasakan puas sebesar 0,037x dibandingkan jika sikap petugas hanya sekadar cukup baik.

\section{Saran}

1. Rumah Sakit Islam Surabaya (RSIS) Jemursari disarankan untuk mempertahankan pelayanan yang sudah baik, serta semakin meningkatkan kualitas skill dan kemampuan petugasnya untuk menjadi yang lebih baik lagi.

2. Meningkatkan mutu atau kualitas pelayanan di instalasi farmasi.

3. Perlu adanya pelatihan-pelatihan dengan tujuan untuk peningkatan mutu pelayanan dikemudian hari.

4. Melakukan monitoring mutu pelayanan rawat jalan persemester dan survei kepuasan pasien secara rutin pertahun.

5. Penelitian mengenai kepuasan pasien terhadap pelayanan farmasi rawat jalan dapat terus dilakukan minimal 6 bulan sekali dengan memakai kuesioner yang sudah diuji. 


\section{REFERENSI}

1. Departemen Kesehatan RI. Keputusan Menteri Kesehatan Republik Indonesia Nomor 129/MENKES/SK/II/2008 Tentang Standar Pelayanan Minimal Rumah Sakit. Jakarta: Depkes RI. 2008.

2. Jacobalis, S. Menjaga Mutu Pelayanan Rumah Sakit. Jakarta: PT Citra Windu Satria. 1990.

3. Megawati, Hariyato T., dan Rachmi A.T. Hubungan Dimensi Mutu Pelayanan Farmasi Rawat Jalan dengan Kepuasan Pasien di RS Baptis Batu: Peran Kepesertaan Asuransi. Jurnal Aplikasi Manajemen. 14 (1), 147160. 2016.

4. Notoatmodjo, S. Metodologi Penelitian Kesehatan. Jakarta: Rineka Cipta. 2010.

5. Parasuraman, A., Zeithaml, V.A. and Berry, L.L. SERVQUAL: A Multiple Item Scale for Measuring Consumer Perceptions of Service Quality. Journal of Retailing 4 (1). 2013.

6. Satrianegara, M.F. Organisasi dan Manajemen Pelayanan Kesehatan. Jakarta: Salemba Medika. 2014.

7. Wiyono, D. Manajemen Mutu Pelayanan Kesehatan. Airlangga University press, Surabaya. 2000. 